\title{
"OS ANIMAIS E OS HOMENS ENQUANTO EMPÍRICOS”: REFLEXÕES EPISTEMOLÓGICAS SOBRE A DIFERENÇA ENTRE A ALMA HUMANA E A ALMA DOS ANIMAIS
}

\author{
Anne-Lise Rey (Lille)
}

\begin{abstract}
RESUMO: O presente artigo enfoca a discussão, ensejada pela publicação do Dictionnaire Historique et Critique, entre seu autor, Pierre Bayle, e Leibniz a propósito dos critérios epistemológicos que permitem distinguir cognição animal de cognição propriamente humana. Trata-se de examinar em detalhe a distinção que, na sequência dessa publicação, Leibniz traçará entre o homem racional caracterizado como aquele apto a produzir silogismos demonstrativos e de alcançar verdades necessárias - e o homem enquanto empírico, a fim de examinar se e de que maneira os critérios epistemológicos que permitem distinguir cognição animal de cognição propriamente humana podem ou não nos permitir circunscrever uma diferença antropológica que permita distinguir o homem do animal.
\end{abstract}

PALAVRAS-CHAVE: Homem; animal; cognição; raciocínio; experiência.

\begin{abstract}
This article is intended to examine the discussion, aroused by the publication of the Dictionnaire Historique et Critique, between its author, Pierre Bayle, and Leibniz concerning the epistemological criteria that allow to distinguish animal cognition and human cognition. We shall examine the distinction that Leibniz tries to establish between man as rational - i. e., man conceived as being able to produce demonstrative syllogisms and to attain necessary truths - and man as empirical, in order to examine whether and in which manner the epistemological criteria that allow to distinguish animal cognition and properly human cognition are or are not able to provide a way to circumscribe an anthropological difference that allows us to distinguish man from animal.
\end{abstract}

KEYWORDS: Man; animal; cognition; reasoning; experience.

1 Gostaria de agradecer aqui a Dominik Perler por seus preciosos conselhos e a School of Historical Studies do Institute for Advanced Study de Princeton pelo período de pesquisa que me permitiu levar a efeito a redação deste artigo. Agradeço igualmente aos editores da Studia Leibinitiana Sonderheft - Band 43 por suas estimulantes observações, que me permitiram aprimorar este texto. Agradeço igualmente a Ulysses Pinheiro e Vivianne de Castilho Moreira pela presente tradução. 
Pierre Bayle aborda a questão da diferença entre a alma dos homens e a alma dos animais e a trata principalmente em dois artigos de seu Dictionnaire historique et critique ${ }^{2}$ o artigo "Pereira" e o artigo "Rorarius".

No início do artigo "Rorarius", Bayle lembra que esse autor quis mostrar $^{3}$ que os animais utilizam melhor a razão que o homem ${ }^{4}$. Ele formula o problema nos seguintes termos:

Aqueles [os fatos singulares relatados por Rorarius] que concernem a habilidade dos animais embaraçam a um só turno os seguidores do Sr. Descartes e os seguidores de Aristóteles: aqueles negam que os animais tenham alma; estes sustentam que eles são dotados de sentimento, de memória e de paixão, mas não de razão 5 .

O problema parece então em primeira instância poder ser colocado assim: ou os animais desprovidos de alma são máquinas, para retomar o

2 Pierre Bayle, Dictionnaire historique et critique, Amsterdam, Reinier Leers, primeira edição, 1697; 4 partes em 2 vol. in-folio. Leibniz parece citá-lo na $2^{a}$ edição de 1702, Rotterdam, Reinier Leers, 3 vol. infolio. Ver por exemplo a carta a Collas, Hanover (17 de março de 1712) onde, a respeito da virtude plástica, ele escreve: "Eu disse algo sobre isso em meu sistema da harmonia preestabelecida, de que o Sr. Bayle fala em seu Dicionário, $2^{\mathrm{a}}$ Edição, artigo Rorarius" < J'en ay dit quelque chose dans mon système de l'harmonie préétablie, dont M. Bayle parle dans son Dictionnaire 2de Edition, article de Rorarius> (AA III B, n. 64, p. 78).

${ }^{3} \mathrm{O}$ livro de Rorarius intitula-se Quod animalia bruta ratione utantur melius homine. É redigido nos anos 1540, mas somente é publicado em 1648.

${ }^{4}$ Eis as primeiras palavras do artigo "Rorarius": "Rorarius (Gerônimo), núncio de Clemente VII junto à corte de Fernando, rei da Hungria, compôs uma obra que merece ser lida. Ele se empenha em mostrar não apenas que os bichos são animais racionais, mas também que eles se servem da razão melhor que 0 homem" < Rorarius (Jérôme), nonce de Clément VIl à la cour de Ferdinand, roi de Hongrie, a composé un ouvrage qui mérite d'être lu. II entreprend d'y montrer, non seulement que les bêtes sont des animaux raisonnables, mais aussi qu'elles se servent de la raison mieux que l'homme> (DHC [5e éd.], t. IV, p. 76). 5 "Ceux [les faits singuliers rapportés par Rorarius] qui concernent l'habileté des animaux embarrassent à la fois les sectateurs de Mr Descartes et les sectateurs d'Aristote : ceux-là nient que les bêtes aient une âme ; ceux-ci soutiennent qu'elles en ont une douée de sentiment, et de mémoire, et de passions, mais non pas de raison" (Ibid., p. 76). Richard Sorabji (1995) mostrou, por um lado, a correlação entre a recusa aristotélica em conceder a razão ao animal e a extensão de sua função perceptiva e, por outro, a importância dessa recusa aristotélica e da posição estóica, similar, a esse respeito, para a concepção que há tempos tivemos da diferença antropológica. Cf. por exemplo p. 1 na introdução: "But the ancient debate seemed to be driven by an Aristotelian and Stoic view of the nature of mankind, that only has reason and belief. It was this that made it necessary to reanalyse so many of the mental capacities that we seem to share with animals". Ele concede igualmente um lugar importante à posição cética em seu livro. 
conteúdo do artigo "Pereira", ou eles têm sensações, memória, dito de outro modo, para retomar uma terminologia aristotélica, uma alma sensitiva, mas não razão ${ }^{6}$.

É nesse contexto que Bayle introduz a posição leibniziana como a mais eficaz contra a negação cartesiana da alma dos animais: ele o apresenta como "o autor que melhor refutou o Sr. Descartes sobre a alma dos animais" ${ }^{7}$, estabelecendo a imortalidade da alma dos animais.

Gostaria de tecer duas observações a partir disso.

Primeiramente, o que acabo de lembrar esquematicamente concerne ao texto principal do artigo "Rorarius", mas a apresentação do problema tal como feita nas observações D (intitulada "há muito tempo que se sustentou que a alma dos animais é racional”") e F ("uma diferença específica entre a alma humana e a dos animais"') parece-me diferente. Com efeito, antes que construir a oposição entre o animal máquina e o reconhecimento da alma sensitiva do animal, as observações colocam incessantemente em evidência os argumentos em favor da ausência de distinção significativa, na literatura antiga e escolástica, entre a alma humana e a alma dos animais. De sorte que o que está em jogo

\footnotetext{
${ }^{6}$ Thierry Gontier (1997), p. 12. apresenta essa oposição entre Rorarius e Pereira como uma oposição entre os partidários da inteligência dos animais (Montaigne) e os partidários dos animais-máquina (Descartes): "Quanto ao leitor do século XVII, este reconhece imediatamente, por trás desses dois autores menores, os verdadeiros 'pais fundadores' dos partidos opostos, que são Montaigne e Descartes: estes não apenas tiveram a audácia de sustentar teses extremas, mas as desenvolveram e tentaram integrálas no seio de um pensamento coerente" <Quant au lecteur du XVIle siècle, il reconnaît immédiatement derrière ces deux auteurs mineurs les véritables 'pères fondateurs' des partis opposés, que sont Montaigne et Descartes : ceux-ci n'ont pas seulement eu l'audace de soutenir des thèses extrêmes, mais les ont développées et ont tenté de les intégrer au sein d'une pensée cohérente>.

7 "L'auteur qui a le mieux réfuté M. Descartes sur l'âme des bêtes".

8 "ll y a longtemps qu'on a soutenu que l'âme des bêtes est raisonnable".

9 "Une différence spécifique entre l'âme humaine et celle des bêtes".
} 
torna-se rapidamente ao mesmo tempo a evidência de um reconhecimento da razão animal, a construção de um território cognitivo comum ao homem e ao animal e, enfim, a necessidade de interrogar a identidade dessa razão comum e, portanto, por vezes, de distinguir duas formas de racionalidade. Como indica o início da observação E do artigo "Pereira": "Quase todos os antigos filósofos ensinaram que essa alma [dos animais] era racional" ${ }^{10}$.

O objetivo deste artigo será tentar determinar de que maneira os critérios epistemológicos que permitem distinguir cognição animal de cognição propriamente humana podem ou não nos permitir circunscrever uma diferença antropológica, isto é, distinguir o homem do animal ${ }^{11}$.

Assim, à exclamação de Bayle:

Não se pode evocar sem horror os desdobramentos desta doutrina: a alma do homem e a alma dos animais não diferem substancialmente, elas são de mesma espécie, uma adquire mais luzes que a outra, mas são apenas vantagens acidentais e dependentes de uma instituição arbitrária ${ }^{12}$.

Leibniz responde tranquilamente escrevendo:

Esses duplos horrores não devem nos assustar. [...] mostrei uma diferença essencial entre a alma dos animais e um espírito tal como a alma racional. As coleções que observamos nos animais não são senão induções ou conclusões contingentes, que podem falhar, e aí não se encontram razões necessárias ou silogismos demonstrativos que fundem as ciências de que são capazes os espíritos ${ }^{13}$.

\footnotetext{
10 "Presque tous les anciens philosophes ont enseigné que cette âme [des bêtes] était raisonnable".

11 Markus Wild (2006) propõe igualmente essa abordagem da antropologia pela reflexão sobre a epistemologia e aborda brevemente Leibniz (cf. pp. 222-224).

12 "On ne peut songer sans horreur aux suites de cette doctrine : l'âme de l'homme et l'âme des bêtes ne diffèrent point substantiellement, elles sont de même espèce, l'une acquiert plus de lumières que l'autre, mais ce ne sont que des avantages accidentels et dépendants d'une institution arbitraire".

13 "Ces doubles horreurs ne doivent point nous épouvanter. [...] j'ai montré une différence essentielle entre l'âme des bêtes et entre un esprit tel qu'est l'âme raisonnable. Les collections que nous remarquons dans les bêtes ne sont que des inductions ou conclusions contingentes, qui peuvent manquer, et l'on n'y trouve
} 
Leibniz indica aí assaz claramente o estatuto que ele concede à distinção das formas de consecução que explicam o "raciocínio" humano suposto comum, ao preço de uma analogia, com o "raciocínio" animal: o reconhecimento da diferença entre induções contingentes e razões necessárias permite pensar a diferença irredutível entre o homem e o animal. Partamos dessa diferença em aparência irredutível para indagar sobre o estatuto metodológico do princípio de continuidade nesse caso $^{14}$.

Minha segunda observação é a seguinte: a questão da alma dos animais conduz Leibniz, em 1702, em suas Observações sobre o artigo "Rorarius", a distinguir o homem racional - que ele define como aquele que é suscetível de produzir silogismos demonstrativos e de alcançar verdades necessárias que derivam de enunciados absolutamente universais - dos "animais e [d]os homens enquanto empíricos”15 (o que deu título a este artigo), que são suscetíveis de uma universalidade fundada sobre a experiência ou a indução, universalidade que não pode ser completamente segura.

Gostaria, portanto, de aplicar-me, em segundo lugar, a compreender como a experiência é suscetível de produzir uma forma de universalidade, o que

point des raisons nécessaires ou syllogismes démonstratifs qui fondent les sciences dont les esprits sont capables" (Extrait du dictionnaire de M. Bayle article Rorarius p. 2599 sqq. de l'Edition de 1702 avec mes remarques", GP IV, p. 527).

${ }^{14}$ L. M. Jorgensen (2009, pp. 223-248) desenvolve a ideia de uma continuidade conceitual: "I provide an account of Leibniz's principle and show how it serves as a methodological principle" (p. 224). E adiante: "Changes in state, from unconscious to conscious, will be continuous in a given mental substance. (I will sometimes call this state consciousness, when a given mental state is itself a conscious mental state). But additionally, there will be a continuum among creatures that are conscious and those that are not. (I will sometimes call this creature consciousness, when a given substance is conscious, by which I mean it has some conscious mental states)" (p. 227).

15 "Bêtes et [d]es hommes en tant qu'empiriques". 
são essas duas formas de universalidade, e se é efetivamente possível, a partir dessa distinção, elaborar uma distinção entre o homem e o animal.

\section{Uma universalidade fundada sobre a experiência e a indução:}

\section{um território cognitivo comum ao homem e ao animal "enquanto} empíricos"

O diálogo que se instaura entre Leibniz e Bayle depois da publicação do Dictionnaire historique et critique aborda uma questão que se encontrará amplamente trabalhada nos $N E$, concluídos mal se completam dois anos depois: aquela de saber como passar do conhecimento empírico, que podem alcançar "os animais e os homens enquanto empíricos", ao conhecimento racional, que é apanágio exclusivo dos homens. Mas nesses textos em resposta a Bayle, a posição de Leibniz não é em absoluto aquela dos NE, pois ela não convoca nem a reflexão como critério distintivo, nem a imaginação como modalidade explicativa do conhecimento empírico. Busco, portanto, compreender em que medida as discussões com Bayle podem ser pensadas como um tipo de laboratório a preparar a consolidação dessas novas modalidades explicativas.

Começarei propondo uma interpretação da passagem já evocada das Observações de Leibniz ao artigo "Rorarius" da edição de $1702^{16}$. Leibniz reage a um trecho desse artigo dizendo que tentou satisfazer ao desejo de Bayle (de propor uma diferença específica entre a alma dos animais e a alma humana) e que ele pensa tê-lo conseguido. Para tornar compreensível o que pretendeu 
fazer, ele recorre a uma comparação que não é evidentemente anódina, visto que faz da questão da alma dos animais uma questão de método. Trata-se de uma comparação que estabelece uma nítida diferença entre as duas.

Tentei explicar-me por uma comparação. Na medicina, há a seita dos Empíricos e as seitas dos Metódicos e Racionais. A primeira não admitia a investigação das causas ou razões, ela se contentava unicamente com fatos ou experiências para dizer: isto serviu ou prejudicou, portanto, poderá ainda servir ou prejudicar em um caso semelhante. Os simples Metódicos quase não se preocupavam com as observações ou experiências, eles acreditavam ter reduzido tudo às causas ou razões. Mas os médicos racionais se empenharam em aperfeiçoar a experiência a ela aliando a investigação das causas. Mostrei que basta que os animais sejam apenas empíricos para poderem fazer tudo o que fazem e que a memória basta para as consecuções das quais eles se servem, esperando de uma experiência nova semelhante às experiências precedentes uma sequência semelhante à sequência das precedentes. Os homens também fazem consequências semelhantes e coroadas de êxito. Mas, como não são necessárias, elas também falham com muita frequência, quando a mesma razão não está presente. A vantagem do homem é, portanto, ser não somente empírico e dotado de memória, que lhe serve para fazer induções, mas também racional e poder efetuar silogismos demonstrativos e conhecer verdades necessárias, que proporcionam enunciações absolutamente universais e infalíveis, o que torna o homem capaz de ciências demonstrativas, do que não se descobre qualquer traço nos animais. Ao passo que os animais e os homens enquanto empíricos são suscetíveis apenas de universalidades fundadas sobre alguma indução ou experiência, mas que não são jamais perfeitamente seguras enquanto não se conhece sua razão ${ }^{17}$.

17 “J'ai taché de m'expliquer par une comparaison. Dans la médecine, il y a la secte des Empiriques et les sectes des Méthodiques et Raisonnables. La première n'admettait point la recherche des causes ou raisons, elle se contentait uniquement des faits ou expériences pour dire : ceci a servi ou nui, donc il pourra encore servir ou nuire dans un cas semblable. Les simples Méthodiques ne se souciaient guère des observations ou expériences, ils croyaient d'avoir tout réduit aux causes ou raisons. Mais les médecins raisonnables ont tâché de perfectionner l'expérience en y joignant la recherche des causes. J'ai montré qu'il suffit que les bêtes soient seulement empiriques pour pouvoir faire tout ce qu'elles font et que la mémoire suffit pour les consécutions dont elles se servent, en attendant d'une expérience nouvelle semblable à des expériences précédentes une suite semblable à la suite des précédentes. Les hommes aussi font des conséquences semblables et qui réussissent. Mais comme elles ne sont point nécessaires, elles manquent aussi très souvent, lorsque la même raison n'y est point. C'est donc l'avantage de l'homme de n'être pas seulement empirique et doué de mémoire qui lui sert à faire des inductions, mais d'être encore raisonnable et de pouvoir faire des syllogismes démonstratifs et connaître des vérités nécessaires, lesquelles donnent des énonciations absolument universelles et immanquables, c'est ce qui rend l'homme capable des sciences démonstratives, dont on ne découvre aucune trace dans les bêtes. Au lieu que les 
Não acompanho inteiramente a interpretação desse trecho proposta por Richard Sorabji pois, embora reconhecendo a comparação entre os médicos empíricos da Antiguidade e os animais, comparação fundada sobre o fato de que eles não possuem qualquer conhecimento da causa e do efeito, ele insiste sobre a singularidade da prática cognitiva humana que, apenas ela, possui propriamente a razão ${ }^{18}$. A meu ver, ele simplifica uma parte do texto. Pareceme, com efeito, que se pode reter três coisas importantes dessa passagem:

- Leibniz propõe uma comparação entre os métodos praticados pelos médicos e o conhecimento que o homem pode alcançar. Como interpretá-lo? Em primeiro lugar, não é anódino que ele tenha escolhido a medicina como modelo de inteligibilidade da compreensão do conhecimento humano. Pensemos, com efeito, no uso da dissecação e da anatomia como uma minuciosa desmontagem do corpo em suas partes, nos séculos XVI e XVII, que fazem da anatomia um modelo de análise da realidade, como bem mostrou Rafael Mandressi (2003). Ou pensemos ainda simplesmente no título da obra de Tschirnhaus de 1687, Medicina mentis.

Há, portanto, um contexto do apelo ao modelo médico como campo mais ou menos metafórico da análise do real. Mas lembremo-nos mais precisamente do que Leibniz escreve, em medicina, a propósito da coleta de

bêtes et les hommes en tant qu'empiriques ne sont susceptibles que des universalités fondées sur quelque induction ou expérience, mais qui ne sont jamais parfaitement sûres, tant qu'on n'en connaît point la raison" (lbid).

18 Sorabji (1995), p. 77: "Leibniz had made an explicit comparison between the empiricist doctors of antiquity and animals. Neither have knowledge of cause and effect. They merely expect good or harm from the same thing in similar circumstances, and this requires only memory. But man, according to Leibniz is different. He has reason, and so goes beyond the universals of induction and experience. Man is capable of producing deductive syllogisms, knowing universal necessary truths and in general of acquiring scientific understanding of the kind described by Aristotle". 
fatos: em substância, ele afirma reiteradamente que ela é indispensável e que, enquanto se espera um conhecimento das razões que nos são atualmente ocultas, ela é o único meio de progredir no conhecimento do corpo humano. Pode-se citar a famosa "Lettre sur la manière de perfectionner la médecine" publicada no Journal des Sçavans de julho de $1694^{19}$, na qual Leibniz exorta os médicos a coletar, à maneira do que fizera Ramazzini em Modena, todas as observações concernentes às doenças, aos sintomas epidêmicos, aos diferentes efeitos dos medicamentos, etc.

Mas pode-se também citar essa passagem bem conhecida dos Novos Ensaios em que Leibniz escreve:

em medicina, os princípios da experiência, quer dizer, as observações, não se poderia exagerar em sua multiplicação, para dar mais ocasião à razão de decifrar o que a natureza nos dá a conhecer apenas pela metade ${ }^{20}$.

Assim, a opção pela referência à medicina como território analógico permitindo auxiliar na compreensão das diferentes vias cognitivas é, ao mesmo tempo, um meio de valorizar as experiências e sua multiplicidade naquilo em que elas permitem à razão compreender a natureza. Leibniz havia escrito igualmente um pouco antes nos Novos Ensaios:

É como se eu dissesse: a medicina é fundada sobre a experiência, portanto a razão não é aí de nenhuma serventia. A teologia cristã, que é a verdadeira medicina das almas, está fundada sobre a revelação, que responde à

\footnotetext{
19 Journal des Sçavans (juillet 1694), pp. 162-163.

20 "en medecine les principes d'experience, c'est à dire les observations, ne sauroient estre trop multipliées, pour donner plus d'occasion à la raison de dechifrer ce que la nature ne nous donne à connoistre qu'à demi" (NE, IV, VII, §15, AA VI, 6, p. 427).
} 
experiência; mas para fazer disso um corpo completo, é preciso acrescentar a ela a teologia natural, que é haurida dos axiomas da razão eterna ${ }^{21}$.

A seguir Leibniz introduz uma axiologia nessa comparação: os médicos puramente empíricos contentam-se em coletar experiências e em nelas identificar o que é útil ou prejudicial. Essa atividade corresponde à atividade cognitiva primeira comum aos animais e aos homens: para explicar as consecuções da atividade animal (sem dúvida, Leibniz procura explicar aqui tudo o que à primeira vista poderia parecer remeter ao domínio da intencionalidade e da antecipação: a armadilha do símio, a vingança do cão pela morte de seu dono, etc., considerando que isso procede da simples consecução, antes que do verdadeiro raciocínio), basta concebê-los como dotados de memória e considerar que a repetição das mesmas experiências permite antecipar as mesmas consequências. Trata-se evidentemente de um meio de limitar o afã de certos escolásticos ou contemporâneos de Leibniz que, da intencionalidade que eles creem desvelar na atividade animal, induzem a marca de uma forma de racionalidade. Mas a questão é aberta na observação E do artigo "Rorarius", quando Bayle escreve, a propósito do Padre Maignan (que considera que, para sentir uma coisa, é preciso conhecer o sentimento que dela se tem):

É preciso, portanto, dizer que a memória dos animais é um ato que os faz rememorar o passado e que lhes ensina que eles se lembram. Como,

21 "C'est comme si je disais, la médecine est fondée sur l'expérience, donc la raison n'y sert de rien. La théologie chrétienne, qui est la vraie médecine des âmes, est fondée sur la révélation, qui répond à l'expérience ; mais pour en faire un corps accompli, il faut y joindre la théologie naturelle, qui est tirée des axiomes de la raison éternelle" (Ibid., §11, AA VI, 6, p. 415. 
portanto, se ousa dizer que eles não têm o poder de refletir sobre seus pensamentos, nem de daí extrair consequências?22

Leibniz não nega que eles possam daí extrair consequências; o que ele recusa aqui, ao menos implicitamente, simplesmente porque o termo está ausente, é o fato de que essa capacidade de daí extrair consequências proceda da reflexão. Isso é uma das coisas que estarão em jogo em sua distinção entre percepção e apercepção, e também uma de suas hesitações: acaso seria preciso atribuir uma forma de apercepção ao animal? Sabe-se que essas questões estão no cerne das análises de Robert McRae (1976), discutidas por Mark Kulstad (1991): seria a apercepção a marca distintiva da atividade intelectual humana que associa inteligibilidade e razão ou ela seria uma condição necessária para a sensação, sendo, nesse caso, partilhada por homem e animal?

Robert McRae formulou o problema nos seguintes termos:

Por um lado, o que distingue os animais de formas inferiores de vida é a sensação ou o sentimento, mas, por outro lado, a apercepção é uma condição necessária da sensação, e a apercepção distingue os seres humanos dos animais ${ }^{23}$.

É essa indeterminação, ou antes, essa ambiguidade, que Mark Kulstad procura destrinchar ${ }^{24}$. Parece que a questão poderia ser formulada em dois

\footnotetext{
22 "II faut donc dire que la mémoire des bêtes est un acte qui les fait ressouvenir du passé, et qui leur apprend qu'elles s'en souviennent. Comment donc ose-t-on dire qu'elles n'ont pas le pouvoir de réfléchir sur leurs pensées, ni d'en tirer des conséquences?" (Ibid.).

23 "On the one hand what distinguishes animals from lower forms of life is sensation or feeling, but on the other hand apperception is a necessary condition of sensation, and apperception distinguishes human beings from animals". McRae (1976), p. 30.

${ }^{24}$ Cf. Também, a propósito dessa questão, M. Miles (1994), pp. 701-724, particularmente pp. 719-720, onde ele reserva um lugar à diferença entre as duas formas de memória: intelectual e empírica.
} 
níveis: seriam as consecuções lógicas observadas nas condutas animais contingentes ou necessárias? E a questão correlata: a reflexão seria própria do homem porque ele tem raciocínios necessários? Kulstad retoma a questão lembrando que, com o exemplo do javali, que "se apercebe" que uma pessoa lhe chama a atenção, nos Novos Ensaios ${ }^{25}$, Leibniz atribui a apercepção aos animais e que ela não é, portanto, reservada apenas aos espíritos, malgrado a "standard view". Ele defende essa interpretação colocando em evidência dois tipos de reflexão ${ }^{26}$. No final, Kulstad propõe uma solução da tensão

${ }^{25} \mathrm{NE}$ II, XXI, 5, AA VI, 6, p.173: "Nos apercebemos de muitas coisas em nós e fora de nós que não entendemos, e as entendemos quando temos delas ideias distintas, com o poder de refletir e daí haurir verdades necessárias. Eis por que os animais não têm entendimento, ao menos nesse sentido, embora tenham a faculdade de se aperceber impressões mais notáveis e mais distinguidas, como o javali se apercebe de uma pessoa que grita para ele, e vai em direção a essa pessoa, da qual ele havia previamente apenas uma percepção nua, mas confusa como de todos os outros objetos que caíam sob seus olhos, e cujos raios atingiam seu cristalino. Assim, a meu ver, o entendimento responde ao que é chamado de intelecto pelos Latinos, e o exercício dessa faculdade é chamado inteleç̧ão, que é uma percepção distinta unida à faculdade de refletir, que não está nos animais. Toda percepção unida a essa faculdade é um pensamento, que não concedo aos animais, não mais que 0 entendimento, de sorte que se pode dizer que a intelecção tem lugar quando o pensamento é distinto. De resto, a percepção da significação dos sinais não merece ser distinguida aqui da percepção das ideias significadas" < Nous nous appercevons de bien des choses en nous et hors de nous, que nous n'entendons pas, et nous les entendons, quand nous en avons des idées distinctes, avec le pouvoir de reflechir et d'en tirer des verités necessaires. C'est pourquoy les bestes n'ont point d'entendement, au moins dans ce sens, quoyqu'elles ayent la faculté de s'appercevoir des impressions plus remarquables et plus distinguées, comme le sanglier s'apperçoit d'une personne qui luy crie et va droit à cette personne, dont il n'avoit eu déja auparavant qu'une perception nue, mais confuse comme de tous les autres objets, qui tomboient sous ses yeux, et dont les rayons frappoient son cristallin. Ainsi dans mon sens l'entendement repond à ce qui chez les Latins est appellé intellectus, et l'exercice de cette faculté s'appelle intellection, qui est une perception distincte jointe à la faculté de reflechir, qui n'est pas dans les bestes. Toute perception jointe à cette faculté est une pensée, que je n'accorde pas aux bestes non plus que l'entendement, de sorte qu'on peut dire, que l'intellection a lieu lorsque la pensée est distincte. Au reste la perception de la signification des signes ne merite pas d'estre distinguée icy de la perception des idées signifiées>. M. Kulstad cita uma outra passagem do Prefácio dos Nouveaux Essais (AA VI, 6, 55), sobre a suspensão da apercepção no momento da morte, que o faz concluir: "Here death is said to lead to a state of confusion on beasts which "suspends apperception". Now apperception could not be suspended in beasts if beasts never apperceived in the first place. Thus the implication (and not simply the suggestion) in this passage is that the souls of at least living beast apperceive" (KULSTAD,1991, pp. 20).

26 "Chapter one also explored a possible way out of this impasse, namely that of distinguishing two different sorts of reflection, one of which humans share with beasts, the other of which is found in humans alone [...]. But here too there are problems, most notably in leaving the question why Leibniz seems never to qualify the statements in which he denies beasts reflection - that is he seems never to say explicitly that 
interpretativa considerando que a sensação presente em todos os animais supõe uma apercepção. Esta última induz a presença de uma reflexão simples que é acompanhada de uma faculdade de produzir inferências empíricas. A apercepção acompanhada de uma forma de reflexão atesta decerto a possibilidade para o animal de produzir inferências, sob a condição de traçar uma diferença entre duas formas de inferência: racionais e empíricas ${ }^{27}$. Pareceme que é precisamente essa diferença que permite pensar essa comunidade epistêmica entre o homem e o animal.

Em 1695, nas "Remarques sur les objections de Foucher, Chanoine de Dijon, contre le nouveau système de la communication des substances", Leibniz havia, de fato, justificado querer manter a diferença entre o princípio sensitivo presente nos animais e aquele presente no homem.

\begin{abstract}
Faço-o porque não acho que os animais façam reflexões que constituam a razão e, dando o conhecimento de verdades necessárias ou das ciências, tornem a alma capaz de personalidade. Os animais distinguem o bem e o mal, tendo percepção, mas não são capazes do bem e do mal moral, que supõem a razão e a consciência ${ }^{28}$.
\end{abstract}

he means to deny beasts only one kind of reflection, namely, focused reflection" (ibid., p. 158). E cita Leibniz: "The soul of a beast has no more reflection than an atom" (GP VI, p. 542).

27 "The statement of the position is never fully explicit, but the basic idea is this. Higher, or focused, reflection is the key to genuine reasoning, with both of these being found in humans but not in lower animals. Lower, or simple, reflection is necessary for consciousness though not sufficient for genuine reasoning. It is required for apperception and also for the memory and attention involved in sensation. Sensation is found in all beasts, and is counted as a sort of apperception (or perception which is apperceived) rather than as a sort of petite perception (or perception which is not apperceived). It brings with it simple reflection and is accompanied by a faculty of performing empirical - but not rational inferences" (ibid., p. 171).

28 "Je le fais parce que je ne trouve pas que les bêtes fassent des réflexions qui constituent la raison et donnant la connaissance des vérités nécessaires ou des sciences, rendent l'âme capable de personnalité. Les bêtes distinguent le bien et le mal, ayant de la perception, mais elles ne sont point capables du bien et du mal moral, qui supposent la raison et la conscience" (Remarques sur les Objections de Foucher, Chanoine de Dijon, contre le nouveau système de la communication des substances, 1695, GP IV, p.492). 
Parece-me que, dentre outras coisas, um dos argumentos em jogo nessa vontade de resguardar uma diferença é o fato de Leibniz reconhecer uma forma de reflexão no princípio sensitivo presente nos homens. Nos "Eclaircissements du nouveau système de la nature et de la communication des substances", ele acrescenta: Mas quando o senhor parece dizer que a alma dos animais deve possuir razão, se se lhe concede sentimento, é uma consequência cuja prova eu não vejo ${ }^{29}$.

Em primeira instância, portanto, a atividade cognitiva animal seria "reduzida" a uma atividade empírica auxiliada pela memória. Essa atividade é comum ao homem e ao animal: no homem, essas consecuções fundadas sobre a repetição das experiências produzem conhecimentos, mas por vezes errôneos, “como não são necessárias”. Essa comunidade cognitiva suscita um primeiro problema: como compreender que se trate da mesma atividade no homem e no animal, se, no homem, essa atividade pressupõe implicitamente o exercício da razão? Não existe atividade empírica que não seria destacada de uma forma de raciocínio. Nesse caso, isso suscita um problema: acaso isso significaria que Leibniz reconheceria implicitamente por isso um tipo de uso da razão no homem e no animal de um modo menor (que não garantiria a certeza de seus conhecimentos) quando sua atividade cognitiva é compreendida "enquanto empíricos”? Parece-me que é a questão do estatuto da percepção nos animais que está em litígio aqui: nesse nível cognitivo, a percepção seria ou não dotada

29 "Mais lorsque vous semblez dire que l'âme des bêtes doit avoir de la raison, si on lui donne du sentiment, c'est une conséquence dont je ne vois point la preuve" (GP IV, p.494). 
de uma forma de reflexividade (mesmo que o termo não seja precisamente utilizado nesse texto)? Isso supõe formular uma alternativa: ou bem se distingue dois níveis de racionalidade, ou bem se conduz à conclusão de que não há faculdade comum ao homem e ao animal.

O segundo ponto é o seguinte: parece que, no trecho da "Observação" de Leibniz ao artigo "Rorarius", não há simetria na comparação entre os métodos médicos e a atividade cognitiva. Com efeito, a caracterização da seita dos metódicos não tem equivalente na descrição da cognição (a não ser que se fizesse da caracterização da produção de silogismos demonstrativos pelo homem a presença nele dos metódicos) e, nesse caso, isso significa que os “racionais” em medicina, isto é, aqueles que "aperfeiçoam a experiência aí acrescentando a investigação das causas", correspondem, por assim dizer, com "vantagem para o homem", a homens que são racionais, quer dizer, empíricos e metódicos. Mas o texto cala-se sobre a articulação no homem dessas duas práticas cognitivas. Eis, a meu ver, o problema colocado em evidência nesse texto.

O terceiro ponto concerne a essas "universalidades que não são jamais perfeitamente seguras enquanto não se conhece sua razão": ao lado das verdades necessárias, das quais é efetivamente possível produzir a razão, o que Leibniz circunscreve aqui não é uma desqualificação desse conhecimento empírico, mas antes a caracterização exata da nossa situação de incerteza na prática cognitiva. Gostaria, então, de interpretar essas universalidades fundadas na experiência enfatizando mais a possibilidade que temos, ao recorrer à experiência, de 
produzir universalidades, do que a incerteza que ela encerra. Acaso essa incerteza derivaria de um conhecimento empírico provisório que seria arrematado, validado por um conhecimento ulterior das verdades necessárias? Nesse caso, estaríamos às voltas com um tipo de empirismo provisional. Ou seria essa incerteza irredutivelmente de uma outra ordem?

Essa questão poderia ser formulada em termos de uma antecipação perceptiva, considerando que as experiências que nos dão uma percepção do mundo nos fazem sentir imperfeitamente por antecipação o que compreenderemos ulteriormente quando conhecermos sua razão. Essa explicação deve ser correlacionada à ideia presente no \} 3 9 7 \text { da Teodiceia de uma } tradução das almas e de sua passagem à razão ${ }^{30}$ : Leibniz justifica essa "elevação

30 Leibniz, Teodiceia, $\S 397:$ :[...] Cheguei mesmo a mostrar um certo meio entre uma criação e uma preexistência inteira, achando conveniente dizer que a alma, preexistente nas sementes desde o começo das coisas, era apenas sensitiva, mas que foi elevada ao nível superior, que é a razão, quando o homem, a quem essa alma deve pertencer, foi concebido, e que o corpo organizado, acompanhando sempre essa alma desde o começo, mas sob muitas mudanças, foi determinado a formar o corpo humano. Julguei também que se poderia atribuir essa elevação da alma sensitiva (que a faz chegar a um grau essencial mais sublime, quer dizer, à razão) à operação extraordinária de Deus. Contudo, será bom acrescentar que eu preferiria prescindir do milagre na geração do homem, bem como na dos outros animais: e isso poderá ser explicado concebendo-se que, nesse grande número de almas e de animais, ou ao menos de corpos orgânicos vivos que estão nas sementes, apenas as almas destinadas a alcançar um dia a natureza humana envolvem a razão que nelas aparecerá um dia, das quais apenas os corpos orgânicos são preformados e predispostos a tomar um dia a forma humana; os outros pequenos animais ou viventes seminais, em que nada tal é preestabelecido, são essencialmente diferentes deles, e nada têm neles de inferior. Essa produção é uma maneira de tradução, mas mais tratável do que aquela que se ensina ordinariamente. Ela não extrai a alma de uma alma, mas apenas o animado do animado; e evita milagres frequentes de uma nova criação, que fariam entrar uma alma nova e pura em um corpo que deve corrompê-la". <J'ai même montré un certain milieu entre une création et une préexistence entière, en trouvant convenable de dire que l'âme, préexistante dans les semences depuis le commencement des choses, n'était que sensitive, mais qu'elle a été élevée au degré supérieur, qui est la raison, lorsque l'homme, à qui cette âme doit appartenir, a été conçu, et que le corps organisé, accompagnant toujours cette âme depuis le commencement, mais sous bien de changements a été déterminé à former le corps humain. J'ai jugé aussi qu'on pouvait attribuer cette élévation de l'âme sensitive (qui la fait parvenir à un degré essentiel plus sublime, c'est-à-dire à la raison) à l'opération extraordinaire de Dieu. Cependant il sera bon d'ajouter que j'aimerais mieux me passer du miracle dans la génération de l'homme, comme dans celle des autres animaux : et cela se pourra expliquer en concevant que dans ce grand nombre d'âmes et d'animaux, ou du moins de corps organiques vivants qui sont dans les semences, ces âmes seules qui sont destinées à parvenir un jour à la nature humaine enveloppent la raison qui y paraîtra un 
da alma sensitiva" 31 como o desenvolvimento de uma razão que estava envolvida apenas nos corpos orgânicos suscetíveis de tomar um dia uma forma humana.

Trata-se claramente de indicar aqui que a diferença das modalidades cognitivas do animal e do homem é a prova da diferença essencial entre a alma dos animais e a alma racional. E, em certo sentido, Leibniz mantém essa diferença distinguindo a indestrutibilidade da alma dos animais da imortalidade da alma dos homens ${ }^{32}$. Mas, sem deixar de afirmá-lo, é preciso ter presente no espírito que Leibniz explica a possibilidade de uma passagem da alma sensitiva à razão, o que supõe uma presença implícita da razão e a possibilidade de seu desenvolvimento quando ela está em germe em certos seres dotados de uma alma sensitiva. Se se interpreta essa passagem da Teodiceia nesses termos, fica difícil sustentar a interpretação sutil de Christian Barth (2014) segundo a qual seria possível fazer coexistir as séries contínuas das almas na natureza e manter a ideia de uma distinção absoluta entre as almas. Essa interpretação, apoiada sobre a ideia de uma influência da posição unitarista de Aquino sobre o pensamento de Leibniz, conduz a propor uma diferença entre a alma sensitiva e a alma racional fundada não em sua constituição ontológica, mas em seus

jour, et que les seuls corps organiques sont préformés et prédisposés à prendre un jour la forme humaine ; les autres petits animaux ou vivants séminaux, où rien de tel n'est préétabli, étant essentiellement différents d'eux, et n'ayant rien d'inférieur en eux. Cette production est une manière de traduction, mais plus traitable que celle qu'on enseigne vulgairement : elle ne tire pas l'âme d'une âme mais seulement l'animé d'un animé ; et elle évite des miracles fréquents d'une nouvelle création, qui feraient entrer une âme neuve et nette dans un corps qui doit la corrompre>.

31 "Élévation de l'âme sensitive".

32 Ibid., § 89. 
conteúdos representativos ${ }^{33}$. Ora, é possível tomar a questão de outro modo, interrogando as modalidades cognitivas mobilizadas por essas almas.

A leitura dessa passagem da Teodiceia coloca três questões:

(1) A antecipação perceptiva poderia realmente ser concebida sem apelo à razão? Se não, será preciso determinar que forma de racionalidade está envolvida aqui.

(2) Como Leibniz explica a passagem do empírico ao racional? É a questão da articulação entre essas duas formas de conhecimento que está em jogo aqui.

(3) Enfim, pode-se ter conhecimento universal sem razão?

Essas três questões se articulam, definitivamente, em torno de um só problema: se o conhecimento empírico é portador de universalidade, acaso ele não pressuporia uma forma de racionalidade que o homem partilharia com o animal?

\section{Em que a diferença antropológica esclarece essa}

\section{universalidade fundada na indução?}

No artigo "Rorarius", Bayle enfatiza toda uma linha interpretativa que, apenas por uma notável exceção à qual retornarei (que concerne ao acesso dos animais ao universal), justifica a existência da razão animal com um certo tipo de argumentação fundada sobre observações e interpretações de passagens

${ }^{33} \mathrm{Ibid}$.: "As I have argued, this is different in the case of Leibniz because for him sensory and rational souls are not absolutely distinct due to different ontological constitutions of their acts [...]. Hence, Leibniz draws the sharp distinction between sensory and rational souls not in terms of the ontological constitutions of these acts, but in terms of representational contents available". 
tomadas de empréstimo a sábios antigos. Ora, ao lado dessa linha interpretativa, existe uma outra que funda o reconhecimento da existência da razão animal sobre bases lógicas. Trata-se, de maneira analógica, de recorrer à “cognição por silogismo" para caracterizar a cognição animal. Indiquemos todavia que não existe, propriamente falando, silogismo nos animais, mas, antes, modalidades de associação. Eu gostaria de partir dessa outra tradição para determinar o sentido que ela confere a essas verdades empíricas universais.

Essa questão de uma capacidade cognitiva comum ao homem e ao animal é uma questão muito antiga que tem sem dúvida suas primeiras raízes na História dos Animais e sobretudo no De Anima de Aristóteles e em seus comentários medievais. Pensa-se de saída em Aristóteles quando, na História dos Animais, escreve o seguinte:

[...] A docilidade e a selvageria, o humor fácil e o mau caráter, a coragem e a covardia, as disposições para o medo e para a temeridade, os desejos, os ardis, os traços de inteligência ${ }^{34}$ [aplicada ao raciocínio], constituem semelhanças com o homem que se encontra em muitos animais, e que lembram semelhanças das quais falamos a propósito das partes dos corpos. Pois certos animais diferem do homem segundo o mais e o menos, e o mesmo se passa com o homem se comparado a um grande número de animais (com efeito, alguns desses estados psicológicos têm mais intensidade no homem, alguns têm mais intensidade nos outros animais), outros, ao contrário, apresentam relações de analogia: assim, ao que, no homem, é arte, sabedoria, inteligência, nos outros animais corresponde alguma outra faculdade natural do mesmo gênero ${ }^{35}$.

34 Uma nota do tradutor da versão francesa, Pierre Louis, indica: "le sens est 'certains traits de ressemblance avec l'intelligence humaine'" (Aristóteles, Histoire des Animaux, t. III, p.1).

35 " [...] La douceur et la sauvagerie, l'humeur facile et le mauvais caractère, le courage et la lâcheté, les dispositions à la crainte ou à la témérité, les désirs, les fourberies, les traits d'intelligence [appliquée au raisonnement], constituent des ressemblances avec l'homme qu'on retrouve chez beaucoup d'animaux, et qui rappellent les similitudes dont nous avons parlé à propos des parties du corps. Car certains animaux diffèrent de l'homme selon le plus ou le moins, et il en va de même pour l'homme comparé à un grand nombre d'animaux (en effet, certains de ces états psychologiques ont plus d'intensité chez l'homme, certains en ont davantage chez les autres animaux), d'autres au contraire présentent des rapports 
Aqui, Aristóteles reconhece a capacidade cognitiva do animal e parece conceber antes de tudo a proximidade entre as atividades intelectuais do homem e do animal, sem deixar de reconhecer a existência de uma diferença de grau.

A lista impressionante que Bayle fornece na observação $E$ (concernente aos dogmas dos Antigos e dos Modernos sobre a alma dos animais) do artigo "Pereira" ou na observação D ("Há muito tempo que se sustentou que a alma dos animais é racional") do artigo "Rorarius" comporta diferentes argumentos em favor da existência da alma racional nos animais. Nesse último artigo, os argumentos são os seguintes: o sentimento não pode subsistir sem entendimento (Estratão e Enesidemo), a diferença entre os animais e os homens não é senão do mais ao menos (Lactâncio), os homens não ultrapassam os animais em razão, colocando na relação à religião a diferença entre o homem e o animal (Arnóbio); "Maimônides acreditou sem dúvida que eles raciocinam, pois atribui-lhes uma espécie de livre-arbítrio"36; os socinianos "dizem contudo que a razão, a liberdade e a virtude se encontram neles imperfeita e analogicamente e que eles se tornam de alguma maneira dignos de pena e de recompensa" ${ }^{37}$. Essa apreensão da proximidade por analogia e imperfeição é central. Ela reaparecerá sob uma outra forma para caracterizar justamente a atividade racional do animal em Roger Bacon.

d'analogie : ainsi, à ce qui chez l'homme est art, sagesse, intelligence, correspond chez certains animaux quelque autre faculté naturelle du même genre" (Aristóteles, História dos Animais, VIII, 1, 588 a18-31). 36 "Maimonide a sans doute cru qu'elles raisonnent car il leur attribue une espèce de franc-arbitre".

37 "Disent néanmoins que la raison, la liberté et la vertu se trouvent en elles imparfaitement et analogiquement et qu'ils se rendent dignes de peine et de récompense, en quelque façon". 
É preciso assinalar muito particularmente a passagem sobre o universal da observação E do artigo "Rorarius", onde Bayle, a propósito da alma dos animais, escreve:

\begin{abstract}
Confessam-nos que ela sente os corpos, que ela os discerne, que ela deseja alguns, que ela abomina outros. É bastante; ela é então uma substância que pensa, ela é então capaz de pensamento em geral: ela pode portanto receber todos os tipos de pensamentos, pode então raciocinar, pode então conhecer o bem honesto, os universais, os axiomas de metafísica, as regras da moral, etc., pois, assim como da cera poder receber a figura de um selo segue-se manifestamente que ela é suscetível da figura de todo selo, é preciso dizer também que, uma vez que a alma é capaz de um pensamento, ela é capaz de todo pensamento ${ }^{38}$.
\end{abstract}

Se o argumento parece por vezes um pouco fraco, na medida em que se apoia sobre o sentimento, a preferência e o discernimento para atestar o pensamento dos animais, quando precisamente, muito frequentemente, é ao apontar uma aptidão distinta dessas que a questão do reconhecimento ou não do animal pensante se formula, essa passagem tem, contudo, o interesse de assinalar que, sob a pluma de Bayle, um acesso ao universal e ao abstrato está presente nos animais.

Na esteira da recepção de Aristóteles na Idade Média, a questão da existência de uma faculdade sensitiva cogitativa presente no animal e de seu equivalente no homem foi particularmente discutida por Roger Bacon, Alberto o Grande e, em certa medida, por Tomás de Aquino. Lembremos brevemente

\footnotetext{
38 "On nous avoue qu'elle sent les corps, qu'elle les discerne, qu'elle en souhaite quelques-uns, qu'elle en abhorre quelques autres. C'est assez; elle est donc une substance qui pense, elle est donc capable de la pensée en général : elle peut donc recevoir toutes sortes de pensées, elle peut donc raisonner, elle peut connoître le bien honnête, les universaux, les axiômes de métaphysique, les regles de la morale etc., car comme de ce que la cire peut recevoir la figure d'un cachet, il s'ensuit manifestement qu'elle est susceptible de la figure de tout cachet, il faut dire aussi que dès qu'une âme est capable d'une pensée, elle est capable de toute pensée" (Dictionnaire Historique et Critique, t. IV , p. 79b).
} 
como foi tratada e, de algum modo, regrada, a questão dessa forma de atividade racional em operação no animal por um certo número de sábios do século XIII cujos trabalhos não eram ignorados por Leibniz (elegemos por prova as referências que ele faz a Roger Bacon, por exemplo, em sua correspondência com Gabriel Wagner em 169739) e de que maneira ela pode auxiliar-nos a precisar o problema com o qual Leibniz se confronta em seu intercâmbio com Bayle.

Na Perspectiva, Roger Bacon distingue uma nova categoria de potências sensitivas na qual ele faz figurar o sentido estimativo, a memória e a faculdade cogitativa. É sob essa condição que ele pode a um só tempo afirmar que o animal é desprovido de inteligência e não utiliza senão os sentidos, e conceber essa atividade cogitativa em operação nos animais. Ele dá alguns exemplos clássicos: a forma hexagonal que a abelha dá ao alvéolo que constrói, a dimensão geométrica da teia da aranha, etc. Ele mobiliza a categoria de sentido cogitativo ou potência cogitativa ("virtus cogitativa"), que é a rainha da potência sensitiva e faz as vezes de razão nos animais:

Cogitatio vero seu virtus cogitativa est in media cellula, quae est domina virtutum sensitivarum, et loco rationis in brutis, et ideo vocatur logistica, id est, rationalis, non quia utatur ratione, sed quia est ultima perfectio brutorum sicut ratio in homine, et quia illi immediate unitur anima rationalis in in hominibus ${ }^{40}$.

O interesse da tese da Perspectiva é indicar claramente a relação dupla dessa faculdade à razão humana: (1) uma relação analógica concernente a sua 
função: ser a faculdade rainha; (2) sua união imediata com a alma racional no homem. Mas, por isso mesmo, R. Bacon mostra também que ela está presente no animal e no homem, e que, portanto, ela também tem uma função no homem. Bacon precisa a seguir que todas as outras potências sensitivas (imaginação, sentido estimativo e memória) são subordinadas à faculdade cogitativa.

Para Roger Bacon, a cogitativa é claramente distinta da imaginação, que lhe fornece elementos necessários ao exercício de sua atividade. Sob sua pluma, encontra-se essa faculdade comum ao homem e ao animal que, no homem, é a provedora dos dados sensíveis de que trata em seguida a alma racional. Como mostrou Rega Wood ${ }^{41}$, reformulando a posição de Bacon nesse contexto de sua relação a Richard Rufus, naturalmente o animal não é considerado por Bacon como podendo generalizar nem deliberar, e Bacon parece terminar por se reportar em última instância ao instinto animal. É nesse contexto que ele elabora uma reflexão sobre a cognição experimental que seria o análogo humano da cogitação animal ${ }^{42}$.

Mas Roger Bacon vai mais longe, visto que, seguindo Alhazen e seu Opticae Thesaurus, ele estabelece três modos gerais do conhecimento sensitivo que têm a particularidade de estar presentes a um só turno no homem e no animal:

(1) a sensação pura, determinada pela simples impressão do objeto sobre os sentidos, como a visão da luz; 
(2) o discernimento que supõe poder comparar várias sensações. Essa comparação supõe o apelo à memória como o que permite distinguir as coisas universais das particulares;

(3) a modalidade pela qual interpretamos o objeto que é atualmente presente. Esta última modalidade é próxima de uma espécie de raciocínio instintivo: que é como um genus arguendi, um gênero de $\operatorname{argumentação}{ }^{43}$.

Esse terceiro modo de conhecimento sensível, Alhazen denomina “cognitio per syllogismum”, o que Bacon considera como uma designação imprópria, visto que o verdadeiro conhecimento silogístico não é acessível senão à alma racional.

Contudo, a partir da identificação dos modos de conhecimento sensitivo, Bacon desenha o mapa do território das modalidades de conhecimento comuns ao homem e ao animal (a contrario, Tomás de Aquino utiliza a comparação para sublinhar a diferença entre a estimativa animal e a cogitativa humana que, ela, pode comparar e combinar as propriedades percebidas pelo sentido interno $)^{44}$.

Bacon atribui ao animal a memória e a capacidade de prever coisas, mas também, como acabamos de ver, um certo poder de raciocinar:

sed quaedam collatio plurimum ad unum ex naturali industria et instinctu naturae, qua plura assimilantur praemissis, et quod unum sit simile conclusioni quia colligitur ex eis, potest bene reperiri apud bruta ${ }^{45}$.

43 "Cognitio vero tertia adhuc est, quae non potest fieri solo sensu, et non est per comparationem ad prius visum, sed absolute considerat praesentem rem..., et est quasi quaedam genus arguendi. Sed in rebus consuetis nos utimur hac cognitione subito, et non percipimus nos arguere, cum tamen arguamus. Homo enim arguit ex natura sine difficultate et labore" (BACON, 1267, p. 81).

${ }_{44}$ Tomás de Aquino compara e distingue por exemplo as consecuções animais e os procedimentos discursivos humanos. Cf. por exemplo Somme théologique, l, q. 78, a. 4.

${ }^{45}$ Bacon (1267), p. 128. 
Os exemplos de emboscadas de símios destinadas à vingança, os fios estendidos da aranha para capturar as moscas parecem ser a marca de uma forma de intencionalidade em operação nas ações animais que conduz a analisá-las como etapas de um procedimento silogístico.

\footnotetext{
Propter ergo hunc finem qui assimilatur conclusioni multa colligit in sua cogitatione quae praemissis similantur. Et sic est de infinitis, in quibus bruta animalia cogitant multa per ordinem respectu unius rei quam intendunt, ac si arguerent apud se conclusionem ex praemissis ${ }^{46}$.
}

De sorte que a constatação de uma identidade, ou ao menos de uma grande proximidade, entre as atividades intelectuais do homem e do animal, fundada sobre a possibilidade de identificar premissas e consequências no seio da atividade cognitiva animal, conduz a reformular o projeto antropológico e a procurar a diferença entre o homem e o animal em âmbitos diferentes das primeiras atividades intelectuais, por exemplo, na relação com Deus ou na moralidade.

Que consequências extrair dessa breve rememoração para ler Leibniz? As definições apresentadas aqui são tomadas como operadores de clarificação do questionamento. Em que elas consistem?

(1) A compreensão da cogitativa como território comum do homem e do animal é o meio para pensar por analogia a faculdade superior da atividade cognitiva animal. Portanto, o animal não será dotado de razão no sentido em que o homem é dotado de razão. Mas ela permite sobretudo pensar o liame e a 
distinção entre a cogitativa e a atividade racional do homem como o que fornece os dados sensíveis. Isso conduz a divisar duas práticas racionais distintas:

- Uma prática racional comum ao homem e ao animal, e, nesse caso, é preciso dizer que o animal é dotado de razão em certo sentido e, a esse título, a questão da universalidade e dos seus graus encontra totalmente seu lugar e seu sentido, colocando-a em relação com a universalidade absoluta das verdades necessárias.

- Uma prática racional própria do homem, que transforma uma certeza relativa em certeza absoluta graças ao princípio de razão: o que justifica falar de antecipação perceptiva, à espera de um conhecimento racional.

(2) Como compreender em Alhazen essa ideia de um "conhecimento por silogismo" que exceda a consecução simples fundada sobre a repetição das mesmas experiências? Acaso teria ela uma atualidade no pensamento de Leibniz?

Desejaria propor uma interpretação em termos de imagem da razão (nos Novos Ensaios, Leibniz falará de “sombra da razão"). É claro que Leibniz identifica essas consecuções como uma prática silogística, e é igualmente claro que ele mantém a diferença com o mesmo argumento (da ausência de acesso por parte do animal à verdade necessária), mas a uniformidade explicativa pode conferir um lugar a essa imagem da razão que nos mostra imperfeitamente o que ela seria no homem.

(3) Averroes não teria afinal razão ao interrogar-se sobre a utilidade de introduzir, como fez Avicena, uma vis aestimativa no seio da atividade cognitiva 
lá onde o conceito aristotélico de imaginação bastava para explicar as diferentes funções em jogo ${ }^{47}$ ?

Mas como Leibniz mobiliza a referência escolástica em seu intercâmbio com Bayle? Acabamos de lembrar brevemente que a questão de um conhecimento universal fundado sobre a indução que os homens e os animais têm em comum é discutida e, para falar francamente, disputada na filosofia escolástica. A questão é saber se e como Leibniz utiliza esse mote.

Parece-me com efeito difícil considerar que os sentidos internos da memória, a imaginação e a vis aestimativa possam ser circunscritos à categoria estrita da sensação. Em outros termos, a posição inicial de uma extensão do domínio da sensação ao ponto de conceber nela capacidades cognitivas que, por analogia, parecem proceder de maneira silogística, conduz a interrogar o que resta à razão para ser definida como razão. Com efeito, como sublinha Dennis Des Chene ${ }^{48}$, um certo número de peripatéticos insiste sobre o fato de que, se a ação do animal é acompanhada de conhecimento (por exemplo quando o cachorro compara uma situação passada com uma situação presente e extrai consequências disso), este é dotado de razão. Lá onde Bayle considera quimérico supor que o animal pode saber sem razão (observação E), o argumento de Pardies que o artigo "Rorarius" explica consiste em dizer que isso não pode bastar, pois, diferentemente do animal, o homem é capaz de pensar em coisas universais, e que essa atividade é o que é próprio da razão humana. Assim, seria

\footnotetext{
47 Sobre essa questão, o artigo de Deborah L. Black (1993), p. 219-58) mostra bem como a questão de uma faculdade estimativa distinta das capacidades perceptivas dos outros sentidos internos é problemática, em particular para al-Ghazali e Averroes. (p. 219).

48 D. Des Chene (2006), pp.215-231 (p. 220).
} 
a distinção entre o conhecimento sensível e o conhecimento inteligível que produziria a real divisão.

Como, nesse caso, compreender o estatuto das verdades empíricas universais nos Novos Ensaios?

\section{As verdades empíricas universais nos Nouveaux Essais}

Lembremos uma reflexão de Bayle:

É evidente a quem quer que saiba julgar as coisas que toda substância que tem algum sentimento sabe que sente; e não seria mais absurdo sustentar que a alma do homem conhece atualmente um objeto sem conhecer que o conhece do que é absurdo dizer que a alma de um cachorro vê um pássaro sem ver que o vê. Isso mostra que todos os atos das faculdades sensitivas são, por sua natureza e por essência, reflexivos sobre si próprios ${ }^{49}$.

É impossível sentir sem sentir que se sente: conceder sensação ao animal é supor, ao mesmo tempo, uma forma de reflexividade nele.

A questão é, portanto, a seguinte: como, nos Nouveaux Essais, Leibniz resolve as aporias abertas por suas discussões com Bayle?

No prefácio aos Novos Ensaios, Leibniz lembra o estatuto dos sentidos para o conhecimento: necessários para nossos conhecimentos atuais, eles são insuficientes para nos dar o conjunto dos nossos conhecimentos atuais, pois se contentam em nos dar exemplos, quer dizer, verdades particulares ou individuais que podem servir de confirmação da razão, mas não podem substituí-la. É a

49 "Il est évident à quiconque sait juger des choses, que toute substance qui a quelque sentiment sait qu'elle sent ; et il ne seroit pas plus absurde de soutenir que l'âme de l'homme connoît actuellement un objet sans connoître qu'elle le connoît qu'il est absurde de dire que l'âme d'un chien voit un oiseau sans voir qu'elle le voit. Cela montre que tous les actes des facultez sensitives sont de leur nature et par essence réflexifs sur eux-mêmes" (Dictionnaire Historique et Critique, "Rorarius", E, t. IV, p. 79a. 
partir daí que Leibniz distingue as consecuções animais das consecuções

humanas:

Os animais são puramente empíricos e não fazem senão se regular por exemplos, pois jamais chegam a formar proposições necessárias, tanto quanto podemos julgar; ao passo que os homens são capazes das ciências demonstrativas. É ainda por isso que a faculdade que os animais têm de fazer consecuções é algo de inferior à razão que está nos homens. As consecuções dos animais são puramente como aquelas dos simples empíricos que pretendem que o que aconteceu alguma vez acontecerá ainda em um caso em que o que lhes afeta é parecido, sem serem capazes de julgar se as mesmas razões subsistem. É por isso que é tão fácil aos homens capturar os animais e que é tão fácil para os simples empíricos cometer falhas. [...] As consecuções dos animais são apenas uma sombra de raciocínio, quer dizer, são apenas conexões de imaginação e passagens de uma imagem à outra, porque, em um evento novo que pareça semelhante ao precedente, espera-se novamente o que se encontrou aí unido outrora, como se as coisas fossem efetivamente ligadas porque suas imagens estão ligadas na memória. [...] Pois a razão é a única capaz de estabelecer regras seguras e suprir o que falta àquelas que não o eram, aí inserindo suas exceções, e de encontrar enfim ligações certas na força das consequências necessárias, o que dá com frequência o meio de prever o evento sem ter necessidade de experimentar as ligações sensíveis das imagens, a que os animais estão reduzidos, de sorte que o que justifica os princípios internos das verdades necessárias distingue ainda o homem do animal ${ }^{50}$.

50 "Les bêtes sont purement empiriques et ne font que se régler sur des exemples, car elles n'arrivent jamais à former des propositions nécessaires autant qu'on en peut juger ; au lieu que les hommes sont capables des sciences démonstratives. C'est encore pour cela que la faculté que les bêtes ont de faire des consécutions, est quelque chose d'inférieur à la raison qui est dans les hommes. Les consécutions des bêtes sont purement comme celles des simples empiriques qui prétendent que ce qui est arrivé quelques fois, arrivera encore dans un cas où ce qui les frappe est pareil, sans être capables de juger, si les mêmes raisons subsistent. C'est par là qu'il est si aisé aux hommes d'attraper les bêtes, et qu'il est si facile aux simples empiriques de faire des fautes. [...] Les consécutions des bêtes ne sont qu'une ombre de raisonnement, c'est-à-dire ce ne sont que connexions d'imagination, et que passages d'une image à une autre, parce que dans une rencontre nouvelle qui paraît semblable à la précédente, on s'attend de nouveau, à ce qu'on y trouvait joint autrefois, comme si les choses étaient liées en effet, parce que leurs images le sont dans la mémoire. [...] Car la raison est seule capable d'établir des règles sûres et de suppléer ce qui manque à celles qui ne l'étaient point, en y insérant leurs exceptions, et de trouver enfin des liaisons certaines dans la force des conséquences nécessaires, ce qui donne souvent le moyen de prévoir l'événement sans avoir besoin d'expérimenter les liaisons sensibles des images, où les bêtes sont réduites, de sorte que ce qui justifie les principes internes des vérités nécessaires, distingue encore l'homme de la bête" (NE, prefácio, AA VI, 6, pp.50-51). 
Ao enfatizar a interpretação das consecuções empíricas como pertencentes ao domínio da imaginação, Leibniz discute explicitamente, mais do que o fazia em suas discussões com Bayle, o fundamento da diferença entre consecuções animais e humanas: a ligação sensível das imagens é assim distinguida e oposta aos "princípios internos das verdades necessárias" 51. Relembrar a distinção, mas também a relação entre imaginação sensível e imaginação racional, é sem dúvida igualmente um meio para pensar a ligação entre verdades empíricas e verdades racionais.

Por aí se compreende a ligação de uma à outra: a sombra da razão opõe-se ao conhecimento da razão das coisas, esse conhecimento de alguma razão da ligação da percepção, inacessível pelas simples sensações. Ele enfatiza, além disso, a oposição entre a experimentação e a indução das verdades universais, de um lado, e, de outro, o conhecimento da necessidade dessas verdades pela razão, dotada de uma “certeza infalível e perpétua" 52 (livro I, cap. I, \10), que é a intelecção. Trata-se do exercício de uma faculdade que é uma percepção distinta unida à faculdade de refletir, que não está nos animais ${ }^{53}$.

No livro IV ${ }^{54}$ dos Nouveaux Essais, Leibniz distingue bem dois sentidos do conhecimento:

(1) Um conhecimento empírico da verdade das coisas que nos faz sentir confusamente a concordância ou o desacordo das nossas ideias;

\footnotetext{
51 "Principes internes des vérités nécessaires".

52 "Certitude immanquable et perpétuelle" (AA VI, 6, p.80).

${ }^{53} \mathrm{NE}$, Livro II, cap.. XXI, §5, AA VI, 6, p.173.

${ }_{54} \mathrm{NE}$, Livro IV, cap. I, §2, AA VI, 6, p.355-356.
} 
(2) Um conhecimento da verdade "no sentido estreito" que, ela, repousa sobre essa concordância das ideias e procede propriamente da Razão sem reservas.

Mas, correlativamente, se nosso conhecimento empírico se verifica constantemente e sem falha a cada repetição da experiência, não poderíamos deduzir daí que ele procede de uma forma de certeza que, sem ser contudo necessária, nos assegura da validade do nosso conhecimento?

É sem dúvida nesse sentido que é preciso compreender a passagem das Veritates physicae $(1678-1680)^{55}$ que concebe graus de universalidade nas verdades sensíveis ou empíricas. Em uma formulação elíptica, Leibniz, nesse texto de juventude, define as induções como verdades sensíveis universais que concordam com vários outros singulares. Ele indica, além disso, que essas induções universais (que podem ser observações ou experiências) têm graus de universalidade e que, por conseguinte, umas são mais certas que outras. O grau de certeza é aí correlato do grau de universalidade.

\section{Conclusão}

Seria preciso lembrar o contexto escolástico no qual tem lugar a discussão entre Leibniz e Bayle para perceber o interesse antropológico do estatuto da fronteira móvel entre razão animal e razão humana: ele conduz seja

55 Gottfried Wilhelm Leibniz, Veritates physicae, AA VI, 4, C1, n. 364, p. 1984: "Inductiones habent suos gradus universalitatis, suntque aliae aliis certiores. Exempli gratia nemo prudens dubitat, quin cras sol sit oriturus; sed rhabarbarum purgare, non aeque certum est, aliquando enim fit ut nonnulli vix fortissimis medicamentis solicitentur. Saepe tamen contenti esse cogimur propositionibus plerumque veris, praesertim in Medicina. Nonnullae inductiones sunt plane insufficientes, et imprudenter illis fiditur. Exempli gratia, quoniam nautae notaverunt suo tempore nullam esse declinationem acus magneticae apud insulas Azores dictas, non ideo concludere debuerunt idem sequentibus temporibus futurum esse, nec proinde debuerunt hujus observationis causa primum meridianum per has insu- las ducere". 
a construir comunidades parciais de práticas cognitivas comungadas entre homem e animal, seja a tentar identificar uma singularidade humana que distinguiria radicalmente o homem do animal. No final, para Leibniz, tratar-seia, como acabamos de ver, da ligação interna das verdades necessárias.

Mas esta análise das universalidades fundadas sobre induções é também - e talvez, mesmo, sobretudo - a ocasião para interrogar sobre o estatuto do conhecimento empírico na economia cognitiva leibniziana. Minha hipótese de uma antecipação perceptiva ou de um empirismo por provisão apoia-se sobre a ideia segundo a qual essa sombra da razão, ou ainda, essa imagem da razão, não tem de ser interpretada somente em termos analógicos ou metafóricos para designar o que pareceria no animal ao que é efetivamente razão no homem. A meu ver, é o único modo de manter essa comunhão empírica dos homens e dos animais a partir da convicção de que a incerteza perceptiva se resolve, no homem, e apenas nele, progressivamente em percepção distinta. É, então, como figura da representação que se dá essa sombra de razão: um traço de um conhecimento por vir que já figura nela.

A questão da diferença antropológica pode, assim, permitir identificar e circunscrever mais de perto a certeza e a universalidade presentes nas verdades empíricas na filosofia de Leibniz. 


\section{BIBLIOGRAFIA}

AQUINO, T. (1984). Somme Théologique. Roguet, A.M. (trad.). Paris: Cerf.

ARISTÓTELES. (1969). Histoire des Animaux, éd. et trad. P. Louis. Paris: Les Belles Lettres.

BACON, R. (1267). Opus maius, ed. J. H. Bridges, Oxford-Edinburgh, 18971900, Vol. II, Perspectiva.

BARTH, C. (2014). "The Great Chain of Souls. Leibniz on Soul Unitarism and Soul Kinds", in D. Perler et K. Corcilius (dir.), Partitioning the Soul in Ancient, Medieval and Early Modern Philosophy. Berlin-New York: De Gruyter.

BAYLE, Pierre. (1697). Dictionnaire bistorique et critique. Amsterdam: Reinier Leers.

BLACK, D. (1993). "Estimation (Wabm) in Avicenna: The Logical and Psychological Dimensions". In: Dialogue XXXII.

Des CHENE, D. (2006). “Animal as Category: Bayle’s Rorarius”. In: J. Smith (dir.), The Problem of Animal Generation in Early Modern Philosophy. Cambridge: Cambridge University Press.

GONTIER, T. (1997). De l'homme à l'animal. Montaigne et Descartes ou les paradoxes de la philosophie moderne sur la nature des animaux. Paris: Vrin.

JORGENSEN, L. M. (2009). "The Principle of Continuity and Leibniz's Theory of Consciousness". In: Journal of History of Philosophy 47/2. 
KULSTAD, M. (1991). Leibniz on Apperception, Consciousness and Reflection, München-Hamden: Philosophia Verlag.

LEIBNIZ, G. W. Sämtliche Schriften und Briefe. Deutschen Akademie der Wissenschaften zu Berlin.

- Die Philosophischen Schriften. Gerhardt. George Olms Verlag.

Hildesheim, 1996.

MANDRESSI, R. (2003). Le regard de Panatomiste, Dissections et invention du corps en Occident. Paris: Éditions du Seuil.

McRAE, R. R. (1976). Leibniz: Perception, Apperception and Thought. TorontoBuffalo: University of Toronto Press.

MILES, M. (1994). "Leibniz on Apperception and Animal Souls". In: Dialogue 23/4.

SORABJI, R. (1995). Animal Minds and Human Morals. Ithaca [N.Y.]: Cornell University Press.

TSCHIRNHAUS, Walther von. (1687). Medicina mentis. Amsterdam.

WILD, M. (2006). Die anthropologische Differenz. Der Geist der Tiere in der frühen Neuzeit bei Malebranche, Descartes und Hume. Berlin: De Gruyter.

WOOD, R. (2007). "Imagination and Experience in the Sensory Soul and Beyond: Richard Rufus, Roger Bacon and their Contemporaries". In: H. Lagerlund (ed.). Forming the Mind: Essays on the Internal Senses and the Mind-Body Problem from Avicenna to the Medical Enlightenment. Dordrecht: Springer. 